\title{
BMJ Open Quality Improving intravenous-to-oral antibiotic switch in children: a team-based audit and implementation approach
}

\author{
Brendan Joseph McMullan (D) , ${ }^{1,2,3}$ Michelle Mahony, ${ }^{1}$ Lolita Java, ${ }^{4}$ \\ Mona Mostaghim, ${ }^{5}$ Michael Plaister, ${ }^{6}$ Camille Wu, ${ }^{3,7}$ Sophie White, ${ }^{1}$ \\ Laila Al Yazidi, ${ }^{1,8}$ Erica Martin, ${ }^{9}$ Penelope Bryant, ${ }^{10,11}$ Karin A Thursky, ${ }^{2,12}$ \\ Evette Buono ${ }^{4}$
}

\begin{abstract}
To cite: McMullan BJ, Mahony M, Java L, et al. Improving intravenousto-oral antibiotic switch in children: a team-based audit and implementation approach. BMJ Open Quality 2021;10:e001120. doi:10.1136/ bmjoq-2020-001120
\end{abstract}

- Additional material is published online only. To view, please visit the journal online (http://dx.doi.org/10.1136/ bmjoq-2020-001120)

Received 20 July 2020 Revised 14 February 2021 Accepted 28 February 2021
Check for updates

(C) Author(s) (or their employer(s)) 2021. Re-use permitted under CC BY-NC. No commercial re-use. See rights and permissions. Published by BMJ.

For numbered affiliations see end of article.

Correspondence to Dr Brendan Joseph McMullan; b.mcmullan@unsw.edu.au

\section{ABSTRACT}

Children in hospital are frequently prescribed intravenous antibiotics for longer than needed. Programmes to optimise timely intravenous-to-oral antibiotic switch may limit excessive in-hospital antibiotic use, minimise complications of intravenous therapy and allow children to go home faster. Here, we describe a quality improvement approach to implement a guideline, with team-based education, audit and feedback, for timely, safe switch from intravenous-to-oral antibiotics in hospitalised children. Eligibility for switch was based on evidence-based guidelines and supported by education and feedback. The project was conducted over 12 months in a tertiary paediatric hospital. Primary outcomes assessed were the proportion of eligible children admitted under paediatric and surgical teams switched within 24 hours, and switch timing prior to and after guideline launch. Secondary outcomes were hospital length of stay, recommencement of intravenous therapy or readmission. The percentage of children switched within 24 hours of eligibility significantly increased from $32 / 50(64 \%)$ at baseline to $203 / 249$ (82\%) post-implementation $(p=0.006)$. The median time to switch fell from 15 hours 42 min to 4 hours $20 \mathrm{~min}$ ( $p=0.0006$ ). In addition, there was a 14-hour median reduction in hospital length of stay $(p=0.008)$. Readmission to hospital and recommencement of intravenous therapy did not significantly change postimplementation. This education, audit and feedback approach improved timely intravenousto-oral switch in children and also allowed for more timely discharge from hospital. The study demonstrates proof of concept for this implementation with a methodology that can be readily adapted to other paediatric inpatient settings.

\section{PROBLEM}

Almost $50 \%$ of children admitted to Australian hospitals are receiving at least one antibiotic at any time, ${ }^{1}$ and unnecessarily prolonged intravenous prescriptions are frequently reported. ${ }^{1-3}$ Switching from intravenous-tooral antibiotics may reduce complications of intravenous therapy and potentially allow children to be discharged home sooner. A key antimicrobial stewardship (AMS) activity is the development of antimicrobial treatment guidelines, including advice on intravenous and oral antibiotics, however, the benefits of these guidelines can only be fully realised with effective implementation.

A systematic review with guidelines for antibiotic duration and intravenous-to-oral switch in children, ${ }^{4}$ was published in 2016 , having been developed by a collaboration of Paediatric Infectious Diseases and AMS physicians and pharmacists: the Australian and New Zealand Paediatric Infectious DiseasesAustralasian Stewardship in Paediatrics group (ANZPID-ASAP). Authors of this study contributed to that publication.

Here, we report a quality improvement (QI) approach which aimed to implement a practice guideline for improved timely and safe switch from intravenous-to-oral antibiotics in children. Implementation of the practice guideline was supported by supplementary educational materials and team-based audit and feedback. The study was conducted in a 150-bed tertiary paediatric referral hospital in Sydney, Australia, which admits infants, children and adolescents less than 18 years. The hospital includes a comprehensive range of generalist and subspecialist teams, including departments of general paediatrics and general surgery. The hospital has an AMS team formed from senior and junior doctors within the hospital paediatric infectious diseases team and a part-time AMS pharmacist. As with other AMS programmes, the team faces competing demands on time and resources.

The aims of this study were:

1. To implement a hospital practice guideline incorporating evidence-based intravenousto-oral antibiotic switch recommendations, using an education campaign and clinical champions, in target groups of general paediatric and general surgical patients. The target was $95 \%$ of guideline-eligible 
patients switched to oral antibiotics within 24 hours of eligibility within 6 months of project implementation

2. To measure and improve intravenous-to-oral antibiotic switch timing prior to and after guideline launch for guideline-listed conditions in target groups, using a continuous audit and feedback process to evaluate and improve guideline uptake

3. To measure secondary outcomes which might be influenced by intravenous-to-oral antibiotic switch, including hospital length of stay and need for recommencement of intravenous therapy or readmission.

\section{BACKGROUND}

Antibiotic overuse is driving a global increase in antimicrobial resistance. ${ }^{5}$ Overuse of intravenous antibiotics in hospitals contributes to this problem, and in children obtaining and maintaining intravenous access is generally more difficult than in adults. In addition, intravenous therapy often keeps children in hospital, with consequences for parents and carers as well as the child.

Switching earlier to oral antibiotics is one approach to address these issues. Successful intravenous-to-oral antibiotic switch initiatives have been described, although predominantly in adult patients. ${ }^{6-9}$ Recommended antibiotic treatment durations for children are often shorter than in adults, for example, most paediatric acute osteomyelitis can be treated with 3-4 days intravenous, followed by oral antibiotics. ${ }^{10}$ For this reason, therapeutic interventions need to be specifically evaluated in children and not simply extrapolated from adult recommendations.

At the time of this study, there were no nationally or locally endorsed guidelines for antibiotic duration and switch in children for use in our institution. Treatment recommendations for antibiotic duration and timing of intravenous-to-oral switch either did not exist or were highly variable, dependent on individual, local and historical practice. The recently published ANZPID-ASAP systematic review and guidelines ${ }^{4}$ for multiple childhood infections provided an opportunity to implement standardised recommendations for more timely intravenousto-oral antibiotic switch and evaluate the effect of this on clinical outcomes that are important to clinicians and patients/carers.

There have been few studies of intravenous-to-oral switch process implementation in children, and those that have been published have been in single conditions $\left(\mathrm{eg}\right.$, osteomyelitis $\left.{ }^{11}\right)$. To date, there have been no studies in children of intravenous-to-oral switch initiatives that address inappropriately long intravenous durations in multiple conditions, using QI methodology.

\section{BASELINE MEASUREMENT}

A retrospective electronic medical record review was undertaken to determine baseline indicators, including intravenous duration and intravenous-to-oral switch. This was done using a preimplementation retrospective cohort of patients, admitted to hospital within 2 years preceding this study and previously sampled in routine hospital antibiotic point-prevalence surveys. Patient inclusion criteria were: age above 28 days, diagnosis of an infection suitable for intravenous-to-oral switch according to the practice guideline, and an ability to tolerate oral medications. This was determined by review of medical record entries on the patients' conditions and their prescribed antibiotics.

A total of 50 patient records from 2015 to 2016 were reviewed in the preimplementation cohort. General paediatric inpatients comprised 35/50 (70\%) of the preimplementation cohort and general surgical inpatients 15/50 (30\%), respectively. The most common indications for antibiotics were appendicitis in 13/50 (26\%) and pneumonia in 14/50 (28\%). Details of indications are shown in table 1 and appendicitis is divided into uncomplicated and complicated disease, as this affects recommended duration of intravenous therapy, according to the practice guideline. Thirty-two of fifty (64\%) patients were switched to oral antibiotics within 24 hours of being eligible. The median time to oral antibiotic switch posteligibility was 15 hours $42 \mathrm{~min}$ (range $0-109$ hours). These provided our baseline figures.

\section{DESIGN}

A multidisciplinary local team was formed to develop and assess strategies required to implement a hospital practice guideline incorporating intravenous-to-oral antibiotic switch recommendations for guideline-listed infections among general paediatric and general surgical inpatients.

Project team members included medical staff, with a medical ID physician lead, general paediatric and general surgical consultant champions and junior doctor representatives, nursing and pharmacy champions, a hospital executive sponsor, and a consumer engagement representative. Expert project methodology and QI input was provided by staff from the New South Wales Clinical Excellence Commission.

The implementation consisted of several elements to support an intravenous-to-oral antibiotic switch intervention. These were: (1) introduction of a local practice guideline, with intravenous-to-oral antibiotic switch recommendations based on the ANZPID-ASAP guideline, ${ }^{4}$ (2) a multidisciplinary education programme for departmental staff, (3) targeted information for parents and (4) audit and feedback. The practice guideline was made available on the hospital intranet and supported by lanyard cards with switching criteria and oral antibiotic doses (online supplemental figures A1 and A2). The multidisciplinary education campaign was supported by general paediatric, general surgical, nursing and pharmacy champions, and included in-services and promotional posters in wards to promote discussion (online supplemental figures A3 and A4). A factsheet for parents was developed which included a checklist for key discussion points around intravenous-to-oral switch (online supplemental figure A5). Clinicians remained free to decide antibiotic therapy, timing of intravenous-to-oral 
Table 1 Indication for antibiotics (categorised according to hospital guideline)

\begin{tabular}{llllllll}
\hline Indication & $\begin{array}{l}\text { Pre-PDSA } \\
\mathbf{n}(\%)\end{array}$ & $\begin{array}{l}\text { PDSA 1 } \\
\mathbf{n}(\%)\end{array}$ & $\begin{array}{l}\text { PDSA 2 } \\
\mathbf{n}(\%)\end{array}$ & $\begin{array}{l}\text { PDSA 3 } \\
\mathbf{n}(\%)\end{array}$ & $\begin{array}{l}\text { Post-PDSA } \\
\mathbf{n}(\%)\end{array}$ & $\begin{array}{l}\text { Total } \\
\mathbf{n}(\%)\end{array}$ & P value* $^{*}$ \\
\hline $\begin{array}{l}\text { Complicatedt appendicitis or } \\
\text { intra-abdominal collection }\end{array}$ & $12(24)$ & $12(23.1)$ & $14(22.2)$ & $25(25)$ & $8(23.5)$ & $71(23.7)$ & 0.96 \\
\hline Pneumonia & $14(28)$ & $7(13.5)$ & $18(28.6)$ & $12(12)$ & $9(26.5)$ & $60(20.1)$ & 0.13 \\
\hline Preseptal cellulitis & $4(8)$ & $8(15.4)$ & $5(7.9)$ & $17(17)$ & $2(5.9)$ & $36(12)$ & 0.34 \\
Appendicitis, uncomplicated & $1(2)$ & $1(1.9)$ & $1(1.6)$ & $19(19)$ & $5(14.7)$ & $27(9)$ & 0.06 \\
\hline Urinary tract infection & $4(8)$ & $5(9.6)$ & $5(7.9)$ & $5(5)$ & $4(11.8)$ & $23(7.7)$ & 0.92 \\
\hline Cellulitis & $4(8)$ & $4(7.7)$ & $1(1.6)$ & $8(8)$ & $2(5.9)$ & $19(6.4)$ & 0.6 \\
\hline Acute cervical lymphadenitis & $2(4)$ & $4(7.7)$ & $7(11.1)$ & $2(2)$ & $3(8.8)$ & $18(6)$ & 0.51 \\
\hline Pyelonephritis & $4(8)$ & $3(5.8)$ & $4(6.4)$ & $1(1)$ & 0 & $12(4)$ & 0.12 \\
\hline Skin abscesses and boils & $1(2)$ & $2(3.9)$ & 0 & $6(6)$ & 0 & $9(3)$ & 0.65 \\
\hline Pleural empyema & 0 & $1(1.9)$ & $2(3.2)$ & $1(1)$ & 0 & $4(1.3)$ & 0.37 \\
\hline Tonsillitis & 0 & 0 & 0 & $4(4)$ & 0 & $4(1.3)$ & 0.37 \\
\hline Acute osteomyelitis & $1(2)$ & $1(1.9)$ & 0 & 0 & 0 & $2(0.7)$ & 0.21 \\
\hline Orbital cellulitis & 0 & 0 & $1(1.6)$ & 0 & $1(2.9)$ & $2(0.7)$ & 0.53 \\
\hline Pneumococcal bacteraemia & $1(2)$ & 0 & $1(1.6)$ & 0 & 0 & $2(0.7)$ & 0.21 \\
\hline Pyomyositis & $1(2)$ & 0 & $1(1.6)$ & 0 & 0 & $2(0.7)$ & 0.21 \\
\hline Brain abscess & $1(2)$ & & 0 & & 0 & $1(0.3)$ & $\mathbf{0 . 0 3}$ \\
\hline Deep surgical site infection & 0 & 0 & $1(1.6)$ & 0 & 0 & $1(0.3)$ & 0.65 \\
\hline Epididymitis & 0 & $1(1.9)$ & 0 & 0 & 0 & $1(0.3)$ & 0.65 \\
\hline Gram negative bacteraemia & 0 & $1(1.9)$ & 0 & 0 & 0 & $1(0.3)$ & 0.65 \\
\hline Lung abscess & 0 & $1(1.9)$ & 0 & 0 & 0 & $1(0.3)$ & 0.65 \\
\hline Mastoiditis & 0 & 0 & $1(1.6)$ & 0 & 0 & $1(0.3)$ & 0.65 \\
\hline Retropharyngeal abscess & 0 & 0 & $1(1.6)$ & 0 & 0 & $1(0.3)$ & 0.65 \\
\hline Superficial surgical site infection & 0 & $1(1.9)$ & 0 & 0 & 0 & $1(0.3)$ & 0.65 \\
\hline Total & $\mathbf{5 0}$ & $\mathbf{5 2}$ & $\mathbf{6 3}$ & $\mathbf{1 0 0}$ & $\mathbf{3 4}$ & $\mathbf{2 9 9}(\mathbf{1 0 0})$ & $\mathbf{N A}$ \\
\hline
\end{tabular}

*The $p$ value is for pre-implementation compared with combined postimplementation data (PDSA1-Post-PDSA).

†Complicated appendicitis is defined as presence of perforation, peritonitis or pus in the peritoneum.

NA, not available; PDSA, Plan-Do-Study-Act.

switch and timing of patient discharge. There were no other significant changes to relevant local guidelines prior to or during the project implementation

The postimplementation period occurred over 12 months. Each week, up to five patients admitted under general paediatric and general surgical teams were randomly sampled weekly from inpatient ward lists and prospectively audited; these patients formed the postimplementation cohort. Records were audited by a primary reviewer (MMa from March to September 2017 and SW from September 2017 to March 2018), checked by a junior medical doctor in the AMS team (LAY) and supported by an Infectious Diseases physician (BJM) available to provide input and resolve any disputes.

Primary outcomes were: (1) the proportion of guideline-eligible patients switched to oral antibiotics within 24 hours of eligibility (original target: $95 \%$ within 6 months of project implementation) and (2) the time taken to switch posteligibility (no predefined target set). Secondary outcomes were the total duration of intravenous antibiotic therapy, length of hospital stay, proportion of patients with intravenous line complications (such as line-related infection, thrombophlebitis or extravasation), readmission within 7 days or recommencement of intravenous antibiotics within 24 hours.

\section{Statistical analysis}

Categorical variables and proportions were compared using $\chi^{2}$ or Fisher's exact tests. A p value of 0.05 (two tailed) was deemed statistically significant. Continuous variables were compared using Wilcoxon rank-sum tests. Statistical analyses were done using Stata V.16.0 (StataCorp) and a statistical process control (SPC) and run chart were generated using QI Charts V.2.0.23 in Microsoft Excel V.16.31.

\section{Patient involvement}

Parents were involved in the design and conduct of this research. The project team included a consumer engagement representative (LJ), who participated in team 


\section{Driver diagram}

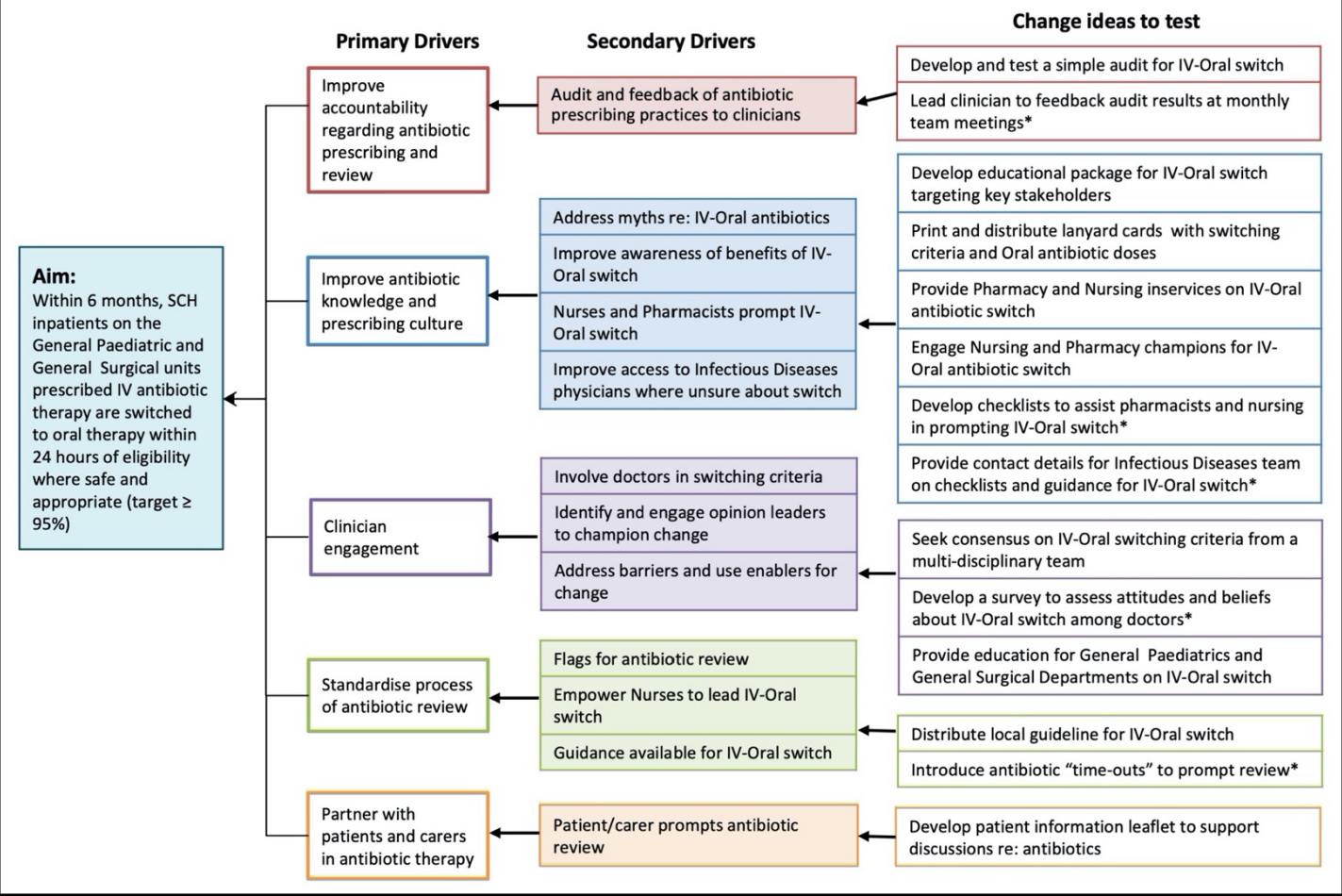

Figure 1 Project driver diagram. *Change ideas not implemented as part of project due to assessment of lower priority or lower feasibility. SCH, Sydney Children's Hospital.

meetings and liaised with the hospital's parent representative group to develop a family-friendly checklist (online supplemental figure A5).

\section{STRATEGY}

The Model for Improvement methodology ${ }^{12}$ was used for project implementation. A driver diagram to illustrate the original project conception and design is shown in figure 1. Change ideas from the driver diagram were assessed and then selected for inclusion in Plan-DoStudy-Act (PDSA) cycles with interventions outlined below. Interventions followed a 'real-world' approach, with overlap of interventions as needed and continuous audit and feedback (via team-based champions) throughout the study. Progress, outcomes, opportunities and barriers were monitored with monthly project-team meetings during the study, which informed ongoing implementation.

\section{Plan for PDSA cycles}

PDSA cycle 1-Practice guideline release and in-service for target medical teams.

PDSA cycle 2-Nursing, hospital executive and consumer engagement.

PDSA cycle 3-Written feedback to teams based on audit results to tailor improvements.

Post-PDSA-Analysis of outcomes during 'business as usual'.

\section{Presentation of feedback}

Feedback was provided to general paediatric and general surgical teams in the form of oral communication from team members and local champions, fed back at monthly unit meetings. This was followed up later with written reports outlining project aims and benefits and team performance, with suggestions for practice improvement, based on recent cases. An example of a written tailored feedback report is shown in online supplemental figure A6.

\section{PDSA cycle 1}

March to May 2017

Plan

The project team submitted the draft practice guideline to the hospital drug and therapeutics committee for approval, which was provided. Key messages for education to medical and pharmacy staff were discussed and presentations were developed and scheduled.

Do

In March 2017, the following processes were implemented: (1) the intravenous-to-oral antibiotic switch practice guideline was released on the hospital intranet and (2) in-service education sessions were delivered to the general paediatrics department and the pharmacy department. 




Figure 2 SPC chart-median time to intravenous-to-oral antibiotic switch. Solid black line=mean (centreline). LCL, lower confidence limit; PDSA, Plan-Do-Study-Act cycle; SPC, Statistical Process Control; UCL, upper confidence limit.

\section{Study}

In the first PDSA cycle the proportion switched within 24 hours was $46 / 53(88 \%)$. The median time from the patient becoming eligible for intravenous-to-oral switch to the switch occurring decreased from baseline, median: 15 hours $42 \mathrm{~min}$ to 6 hours and $0 \mathrm{~min}$. The indication for antibiotics in this and subsequent cycles is shown in table 1. Time to intravenous-to-oral switch and variation over time is shown in figure 2. The statistical process control chart in figure 2 displays non-random variation during this period, indicating change is likely due to the interventions (note: the mean rather than median time intravenous-to-oral switch is displayed on this chart, by convention). The percentage of patients achieving switch within 24 hours of eligibility is shown in figure 3 and also shows an improvement compared with baseline assessment.

\section{Act}

We noted interventions to date appeared successful in the short term and planned to continue the engagement strategy, audit and feedback as originally outlined.



Figure 3 Run chart-percentage of eligible patients switched to oral antibiotics within 24 hours connected line=percentage of patients switched by month (prospective cohort). Dotted line is median switch in baseline cohort. Solid line=median switch (prospective cohort). PDSA, Plan-DoStudy-Act.
PDSA cycle 2

June to August 2017

Plan

We planned to make lanyard cards with a summary of practice guideline recommendations in this cycle to increase availability of and attention to the practice guideline. We also planned to directly engage heads of departments beyond general paediatrics and surgery and engage nurses directly, aiming to also influence the general hospital milieu. We planned to display project information as posters on walls and make educational information for parents/carers available.

\section{Do}

In June-July 2017, the following processes were implemented: (1) lanyard cards were delivered to doctors in general paediatrics and surgery; (2) the medical lead gave a presentation at hospital heads of hospital departments meeting, with support from the executive sponsor; (3) parent information was finalised and distributed to wards; (4) a project promotional poster was finalised and displayed on wards; (5) nursing information packs were distributed and (6) the Nurse champion led in-service education for nurses.

\section{Study}

In the second PDSA cycle, there was a decrease compared with cycle 1 in the proportion switched within 24 hours to $45 / 63(71 \%)$ and increase compared with cycle 1 in the median time to switch to 14 hours $22 \mathrm{~min}$, though this did not rise above baseline. There was also more variation noted in the timing of switch (figure 2). This was unexpected and contributing factors were assessed. Although the spectrum of indications did not change significantly between the preintervention and postintervention periods (with the exception of a single brain abscess in the preintervention period), there was proportionately more pneumonia in cycle 2 compared with cycle $1(18 / 63(28.6 \%)$ vs $7 / 52(13.5 \%))$. We noted concerns from clinicians that there was pressure to make beds available, with subsequent increased demands on medical team time and fears of discharging patients with ongoing respiratory symptoms prematurely. Continuation of intravenous therapy for admitted patients relieved the perceived pressure for early discharge. The project team noted this occurred in context of winter with an especially severe influenza season locally but ultimately reflected clinician behaviour. It was thus necessary to address this as an unanticipated but potentially modifiable factor in relation to the ultimate success of the project.

\section{Act}

The interventions, previously successful, appeared vulnerable to clinician behavioural change, at least partially in response to an increase in presentations and severe respiratory infections during winter, and the sustainability of the project was threatened by this. We had provided oral feedback but not yet tailored written feedback and 
reinforcement to general paediatric and general surgical teams. We also had not yet managed to present formally to the general surgical department, nor had we spoken to hospital bed managers. We planned to gather further information from issues raised during PDSA cycle 2, including with informal discussion with representative clinicians and to address these issues explicitly in the next cycle.

\section{PDSA cycle 3}

\section{September 2017 to January 2018}

Plan

We planned tailored oral and written feedback of audit results (delivered via email, content as in online supplemental figure A6) to general paediatric and general surgical teams, with practice suggestions for intravenous-to-oral switch. We also planned to make the lanyard cards more widely available to junior medical officers (JMOs), as there was a risk that rotating JMOs, newly arrived in target departments, may have not received them.

\section{Do}

In August 2017, in-service education was delivered to the general surgical department. In September 2017, the following processes were implemented: (1) in-service education was delivered to the Emergency Department; (2) there was further distribution of lanyard cards to prescribers; (3) a first round of tailored written feedback of audit results was delivered to teams and (4) the project was reviewed and formally discussed at AMS team meetings and promoted on AMS rounds from this time. In December 2017, a second round of tailored written feedback of audit results was delivered to teams. During this period, we clarified explicitly with clinicians and hospital bed managers that patients could remain in hospital as clinically indicated, whether or not they were receiving oral antibiotics and ensured this information was understood among all levels of clinical staff.

\section{Study}

In the third PDSA cycle, the proportion switched within 24 hours increased to $82 / 100$ (82\%), substantially recovering previous improvement gains. The median time to intravenous-to-oral switch decreased to $3 \mathrm{~min}$, often occurring at the point of guideline-determined eligibility. Once again, we observed eight or more datapoints below the centreline indicating non-random variation.

Although the third PDSA cycle activities were overall less intensive than those in the first two cycles, they were more effective, achieving a much-improved result. We attributed the success to the tailored feedback, increased accessibility and awareness of the practice guideline, engagement of the AMS team and, to some extent, easing of external pressures such as bed availability. This cycle was also somewhat longer, incorporating a hospital low activity period which occurred in late December and throughout January.

\section{Act}

We planned next to review study outcomes finally without further targeted intervention efforts and a return to usual care.

\section{Post-PDSA phase}

\section{February to March 2018}

In this phase, there were no specific activities conducted, though the practice guideline, posters and lanyard cards remained available for staff.

Intravenous-to-oral switch occurred within 24 hours for $30 / 34(88 \%)$ patients in the post-PDSA cycle, significantly above the baseline figure of $32 / 50(64 \%)$ (OR $4.2,95 \%$ CI 1.3 to $13.9, \mathrm{p}=0.01)$. The median time to intravenous-to-oral switch increased compared with PDSA cycle 3, however, from $3 \mathrm{~min}$ to 13 hours $7 \mathrm{~min}$ but remained below the baseline of 15 hours 42 mins.

We reflected that despite the median time to intravenousto-oral switch increasing in this business-as-usual period, previous efforts, combined with ensuring availability of project materials in this period resulted in a significant and sustained improvement in the proportion switched within 24 hours, but that maximum effectiveness would require some ongoing efforts. We planned to continue to make the project materials available to hospital staff and include promotion of the practice guideline and materials at future medical and nursing orientation sessions. Intravenous-to-oral antibiotic switch performance would become part of the AMS team's routine activities with periodic assessments and feedback to teams in future using materials developed during the project.

\section{RESULTS}

Before-and-after analysis

We reviewed the implementation cohort as a whole and compared this to our baseline cohort. A total of 249 records were reviewed prospectively between March 2017 and March 2018. General paediatric inpatients comprised $151 / 249(61 \%)$ of the prospective cohort with $98 / 249$ (39\%) general surgical inpatients. The most common indications for antibiotics in these groups remained pneumonia in 49/249 (20\%) and appendicitis in 84/249 $(34 \%)$. Our audits were able to obtain complete data for the variables analysed.

\section{Primary outcomes}

There was a significant overall reduction in time to switch from a median of 15 hours $42 \mathrm{~min}$ preimplementation to 4 hours $20 \mathrm{~min}$ postimplementation $(\mathrm{p}=0.0006)$ during the 12-month study period (table 2 ). The proportion of patients who were switched within 24 hours of eligibility significantly increased from 32/50 (64\%) preimplementation to $203 / 249(82 \%)$ postimplementation, $(\mathrm{p}=0.006$, shown in table 2). Time to intravenous-to-oral switch and variation over time, shown in figure 2 , displayed nonrandom variation and we concluded improvements seen were likely due to the interventions. The percentage of 
Table 2 Outcome measures

\begin{tabular}{|c|c|c|c|c|}
\hline Measure & $\begin{array}{l}\text { Preimplementation } \\
(\mathrm{n}=50)\end{array}$ & $\begin{array}{l}\text { Postimplementation } \\
(\mathrm{n}=249)\end{array}$ & $P$ value & OR \\
\hline \multicolumn{5}{|l|}{ Primary outcomes } \\
\hline $\begin{array}{l}\text { No of eligible patients switched } \\
\text { within } 24 \text { hours* }\end{array}$ & 32 (64\%) & $203(82 \%)$ & 0.006 & $2.48(1.2-5)$ \\
\hline $\begin{array}{l}\text { Length of hospital admission } \\
\text { (median) }\end{array}$ & 78 hours & 63 hours $51 \mathrm{~min}$ & 0.008 & NA \\
\hline $\begin{array}{l}\text { Intravenous line-associated } \\
\text { complications }\end{array}$ & $0(0 \%)$ & $3+(1 \%)$ & 0.44 & (Undefined) \\
\hline
\end{tabular}

Bold values are statistically significant.

${ }^{*}$ Time and eligibility to switch from intravenous-to-oral medications after meeting guideline criteria for switch. †One patient had extravasation injury and two patients had thrombophlebitis.

NA, not available.

patients achieving switch within 24 hours of eligibility, shown in figure 3 demonstrates variation over time but a clear improvement overall, compared with baseline assessment.

\section{Secondary and additional outcomes}

The median duration of total intravenous therapy significantly decreased from 62 hours 45 min preimplementation to 48 hours and 0 min $(p=0.01)$. The median length of inpatient hospital admission correspondingly decreased from 78 hours preimplementation to 63 hours $51 \mathrm{~min}(\mathrm{p}=0.008)$, representing approximately 14 hours' reduction in both measures (table 2 ). There were no significant changes in intravenous line-related complications, which were rare. Readmissions and recommencement of intravenous therapy did not increase significantly postimplementation (table 2). An additional unmeasured but anecdotal outcome was a report from the AMS and project teams that fewer children with certain infections were commenced on intravenous therapy, following evidence-based and guideline-recommended indications for selected conditions where oral antibiotics could be used immediately. ${ }^{4}$

\section{Resource use and costs}

The implementation required an investment of staff time from the project team to attend meetings, plan and review interventions and engage target staff with audit and feedback, and this was most substantial at the beginning of the project. Although we did not access direct or indirect costs arising from the implementation or related to the intervention, the reduction of hospital length of stay and intravenous antibiotic use for children during implementation is likely to have avoided considerable costs for the institution, as well as for families of children.

\section{LESSONS AND LIMITATIONS}

This study is the first, to our knowledge, to address inappropriately long intravenous antibiotic durations in multiple conditions affecting hospitalised children using QI methodology. The project team was thus able to rely on prior knowledge for the methodology but needed to be flexible to adapt interventions to team-based and contextual factors during the study. The major outcomes were a reduction of intravenous antibiotic use and improved timeliness of switch, following implementation, with reduction in hospital length of stay, and without any signals of potential harm.

In context, a study in adult patients using a printed checklist reported a $19 \%$ reduction in intravenous treatment days ${ }^{7}$ but the study did not have the capacity to assess whether switch occurred when appropriate according to evidence-based guidelines, as our study did. Another study in children used a multifaceted intervention strategy to successfully improve oral antibiotic stepdown for children with osteomyelitis. ${ }^{11}$ This study included a small number of children with osteomyelitis and thus was unable to demonstrate the applicability of its methodology to a broad range of infections in children.

Our project team explicitly sought input from clinical champions who could help implement the guideline alongside their peers. After completing the project, we sought specific feedback from these champions. The general paediatric clinical champion (MP) reflected that educating staff on the existence of a new resource 
(the practice guideline), making it readily available and repeated reference to it, was an effective strategy to ensure its use in everyday practice and that discussing the evidence-based resource with peers at departmental meetings gave clinicians confidence to change to oral antibiotics at the recommended time. The general surgical clinical champion (CW) noted that changing practice and habits can be slow and needs continual reminders. CW also recalled that the departmental reports were particularly helpful but acknowledged that external factors had and continue to have an effect on practice and there is an ongoing risk of slipping back into old habits. The nursing clinical champion (EM) reported implementation barriers for nurses included staff turnover, time constraints and perceived etiquette around nurse/doctor hierarchy and prescribing decisions. These barriers were overcome in our project by presentation of hospital policy and evidence-based data on improved patient outcomes and the role of nurses in AMS. Nurses were motivated by improved discharge times, reduced complications associated with intravenous access and ultimately their role as patient advocate for an improved and safer patient journey.

Our study had limitations, as a single-centre study with a convenience baseline sample, retrospectively reviewed. A substantial winter influenza season influenced intravenous-to-oral switch decision making in unanticipated ways and this needed to be addressed during the project. We managed this successfully during the project but noted this would likely need to be reinforced during subsequent winters and other periods of intense respiratory infections in future. Tailored messaging and interventions based on audit data for specific teams appeared most effective to improve outcomes, but their maximum impact was during the time they were provided. We achieved our original target rate of $95 \%$ intravenousto-oral switch within 24 hours of eligibility at several points (figure 3), though could not sustain it at this level throughout the study, indicating that maximal benefit could only be obtained with ongoing targeted efforts. Nonetheless, outcomes remained improved overall throughout the study, compared with baseline, despite relatively modest resources invested, and even without any specific ongoing active interventions in the postPDSA period.

We believe the study demonstrates a proof of concept for this approach of practice guideline implementation with intensity and types of efforts adapted to meet current needs. This methodology is within the capacity of a small implementation team, with resources developed (online supplemental appendix) that can readily be adapted to other paediatric inpatient settings.

\section{CONCLUSIONS}

In this study, we successfully implemented a hospital practice guideline with evidence-based intravenous-tooral antibiotic switch recommendations, supported by an education campaign and clinical champions. The approach described here supported an improvement in timely, appropriate intravenous-to-oral antibiotic switch in children, over the 12-month study period. Our finding that 14 hours' median reduction in hospitalisation postimplementation matched 14 hours' median reduction in intravenous therapy, suggests that duration of intravenous antibiotics influences length of inpatient stay for children, in our setting. Secondary outcomes measured indicated our process was safe and had potential to reduce hospital length of stay without excess need for recommencement of intravenous therapy or readmission. Although we did not analyse cost or quality of life measures in this study, our findings of increased timely switch with reduced length of stay suggest that successfully implemented intravenous-to-oral antibiotic switch is also likely to be associated with cost savings for hospitals and potentially improved quality of life for children and their families, and these issues merit further study.

Author affiliations

${ }^{1}$ Department of Immunology and Infectious Diseases, Sydney Children's Hospital Randwick, Sydney, New South Wales, Australia

${ }^{2}$ NHMRC National Centre for Infections in Cancer, Sir Peter MacCallum Department of Oncology, University of Melbourne, Peter MacCallum Cancer Institute, Melbourne, Victoria, Australia

${ }^{3}$ School of Women's and Children's Health, University of New South Wales, Sydney, New South Wales, Australia

${ }^{4}$ Medication Safety, Clinical Excellence Commission, Sydney, New South Wales, Australia

${ }^{5}$ Pharmacy Department, Sydney Children's Hospital Randwick, Sydney, New South Wales, Australia

${ }^{6}$ Department of General Paediatrics, Sydney Children's Hospital Randwick, Sydney, New South Wales, Australia

${ }^{7}$ Department of Paediatric Surgery, Sydney Children's Hospital Randwick, Sydney, New South Wales, Australia

${ }^{8}$ Child Health Department, Sultan Qaboos University, Muscat, Oman

${ }^{9}$ Department of Nursing, Sydney Children's Hospital Randwick, Sydney, New South Wales, Australia

${ }^{10}$ Infectious Diseases and Hospital in the Home Departments, The Royal Children's Hospital, Melbourne, Victoria, Australia

${ }^{11}$ Clinical Paediatrics, Murdoch Childrens Research Institute, Melbourne, Victoria, Australia

${ }^{12}$ National Centre for Antimicrobial Stewardship, The Peter Doherty Institute for Infection and Immunity, Melbourne, Victoria, Australia

Acknowledgements The authors thank the staff, patients and families at Sydney Children's Hospital. Particular thanks for their assistance are due to Laura Griffin and Cathy Lovell.

Contributors BJM planned and conducted the study, reviewed the data and cowrote the manuscript, and submitted the study and is responsible for overall content. MMa, conducted the study, reviewed the data and co-wrote the manuscript. LJ planned and conducted the study and cowrote the manuscript. MMo conducted the study and cowrote the manuscript. MP, CW, SW, LAY and EM conducted the study, reviewed the data and cowrote the manuscript. PB reviewed the data and cowrote the manuscript. KAT reviewed the data and cowrote the manuscript. EB planned and conducted the study, reviewed the data and cowrote the manuscript.

Funding The authors have not declared a specific grant for this research from any funding agency in the public, commercial or not-for-profit sectors.

Competing interests None declared.

Patient consent for publication Not required.

Ethics approval SCHN Human Research Ethics Committee approved this project as a Quality Improvement study. 
Provenance and peer review Not commissioned; externally peer reviewed.

Data availability statement Data may be obtained from a third party and are not publicly available.

Supplemental material This content has been supplied by the author(s). It has not been vetted by BMJ Publishing Group Limited (BMJ) and may not have been peer-reviewed. Any opinions or recommendations discussed are solely those of the author(s) and are not endorsed by BMJ. BMJ disclaims all liability and responsibility arising from any reliance placed on the content. Where the content includes any translated material, BMJ does not warrant the accuracy and reliability of the translations (including but not limited to local regulations, clinical guidelines, terminology, drug names and drug dosages), and is not responsible for any error and/or omissions arising from translation and adaptation or otherwise.

Open access This is an open access article distributed in accordance with the Creative Commons Attribution Non Commercial (CC BY-NC 4.0) license, which permits others to distribute, remix, adapt, build upon this work non-commercially, and license their derivative works on different terms, provided the original work is properly cited, appropriate credit is given, any changes made indicated, and the use is non-commercial. See: http://creativecommons.org/licenses/by-nc/4.0/.

ORCID iD

Brendan Joseph McMullan http://orcid.org/0000-0001-5144-3416

\section{REFERENCES}

1 Osowicki J, Gwee A, Noronha J, et al. Australia-Wide point prevalence survey of the use and appropriateness of antimicrobial prescribing for children in hospital. Med J Aust 2014;201:657-62.

2 Barry E, Smith SM. Potentially inappropriate prescribing in children. Fam Pract 2015;32:603-4.
3 McMullan BJ, Hall L, James R, et al. Antibiotic appropriateness and guideline adherence in hospitalized children: results of a nationwide study. J Antimicrob Chemother 2020;75:738-46.

4 McMullan BJ, Andresen D, Blyth CC, et al. Antibiotic duration and timing of the switch from intravenous to oral route for bacterial infections in children: systematic review and guidelines. Lancet Infect Dis 2016;16:e139-52.

5 O'Neill J. Review on antimicrobial resistance. Antimicrobial Resistance: Tackling a Crisis for the Health and Wealth of Nations, 2014.

6 Buyle FM, Metz-Gercek S, Mechtler R, et al. Prospective multicentre feasibility study of a quality of care indicator for intravenous to oral switch therapy with highly bioavailable antibiotics. $J$ Antimicrob Chemother 2012;67:2043-6.

7 Mertz D, Koller M, Haller P, et al. Outcomes of early switching from intravenous to oral antibiotics on medical wards. J Antimicrob Chemother 2009;64:188-99.

8 Rodriguez-Pardo D, Pigrau C, Campany D, Diaz-Brito V, et al. Effectiveness of sequential intravenous-to-oral antibiotic switch therapy in hospitalized patients with gram-positive infection: the sequence cohort study. Eur J Clin Microbiol Infect Dis 2016;35:1269-76.

9 Thompson C, Zahradnik M, Brown A. The use of an IV to PO clinical intervention form to improve antibiotic administration in a community based Hospital. BMJ Open Quality 2015;4:u200786:w2247.

10 Peltola H, Pääkkönen M, Kallio P, et al. Short- versus long-term antimicrobial treatment for acute hematogenous osteomyelitis of childhood: prospective, randomized trial on 131 culture-positive cases. Pediatr Infect Dis J 2010;29:1123-8.

11 Brady PW, Brinkman WB, Simmons JM, et al. Oral antibiotics at discharge for children with acute osteomyelitis: a rapid cycle improvement project. BMJ Qual Saf 2014;23:499-507.

12 Berwick DM. A primer on leading the improvement of systems. BMJ 1996;312:619-22. 